\title{
“Desperately NeEd a CAR": ANALYZing CROWDFunding CAMPAIGNS FOR CAR PURCHASES AND REPAIRS ON GOFUNDME.COM
}

\section{A PREPRINT}

Nicholas J Klein, Ph.D.

Assistant Professor

Department of City and Regional Planning

College of Architecture, Art, and Planning

Cornell University*

\author{
Minh Tran, MRP \\ Department of City and Regional Planning \\ College of Architecture, Art, and Planning \\ Cornell University
}

\author{
Sarah Riley \\ Ph.D. Student \\ Department of Information Science, \\ Cornell University
}

August 8, 2020

\section{Suggested citation:}

Klein, N. J., Tran, M., Riley, S. (2020). "Desperately Need a Car": Analyzing crowdfunding campaigns for car purchases and repairs on Gofundme.com. Travel Behaviour and Society, 21, 247-256. doi.org/10.1016/j.tbs.2020.07.004

\begin{abstract}
Our study explores the phenomenon of using the crowdfunding website GoFundMe.com to raise money to purchase and or repair a personal vehicle. We use both text mining and qualitative analysis methods to ask three research questions about GoFundMe campaigns from the United States created in 2018 and 2019. First, how do campaigners on GoFundMe describe their need for personal vehicles? Second, what precipitating events led them to seek crowdfunding for a car purchase or repair? Third, what are broader contexts for these requests for financial assistance?

We find that many campaigns describe several interrelated crises, complications, or challenges that the campaigners faced, such as medical conditions, loss of employment, and housing crises. Most campaigners are without a functioning car because of an unexpected event - a car crash, a breakdown, or repairs piling up—combined with their inability to pay for the repairs or replacement. Finally, campaigners wanted cars to travel to work and school, to chauffeur children, and to access medical care.
\end{abstract}

Keywords car ownership $\cdot$ crowdfunding $\cdot$ qualitative analysis $\cdot$ text mining

${ }^{*}$ Corresponding author $\mathrm{n} . \mathrm{klein} @ \operatorname{cornell}$. edu 


\section{Introduction}

In 2015, a campaign titled "Help James Robertson Get a Car" on the crowdfunding website GoFundMe went viral (GoFundMe.com, 2015). The plea described Detroit resident James Robertson's 21-mile walk each workday since his car had broken down ten years earlier. The national media picked up Robertson's story, and the campaign went on to raise more than $\$ 350,000$ from over 13,000 donors. While the attention and success make the Robertson GoFundMe campaign an anomaly, using GoFundMe to appeal for help to buy or pay for repairs to a personal vehicle is not.

We explore the precarity of car ownership among low-income households in the United States by analyzing GoFundMe campaigns to raise money for purchasing or repairing a personal vehicle. Our research builds on the literature about why low-income households want cars, the financial stresses of buying and maintaining cars, and the reasons these households experience transitions into and out of car ownership. We take as a starting point that low-income households are much more likely than higher-income households to transition into and out of car ownership, but researchers know little about the causes and consequences of these car ownership transitions for low-income households (Klein and Smart. 2017, 2019).

We analyzed 335 personal narratives and related metadata from GoFundMe campaigns posted from January 2018 through July 2019 to examine three research questions. First, how do campaigners on GoFundMe describe why they need personal vehicles? Second, what were the precipitating events that led them to seek crowdfunding for a car purchase or repair? Finally, what are the broader contexts for these requests for financial assistance?

Our research suggests that campaigners on GoFundMe sought funding to replace or repair their cars for many of the same reasons that others want and need cars. They want cars to get to and from work and school, to access medical care, and to take care of their children. The most common reason they were without a functioning car was that they could not afford to repair or replace a car after an unexpected event: a car that broke down, needed repairs, was in a crash, or was stolen. Not having a working car compounded the campaigners' other financial, medical, and personal struggles.

The following two sections describe the relevant literature on car ownership, the GoFundMe site, and crowdfunding platforms. Next, we outline the methods used in this analysis. We then describe the findings in two parts. First, we document the uses of GoFundMe to raise money for car purchases. Second, we use quantitative and qualitative methods to analyze the content of these campaigns. Finally, we conclude with a discussion of the relevance for research and practice.

\section{Car Ownership Among Low-Income Households}

The most important factor influencing whether a household owns a car is its level of income. In the U.S., most households that can afford to own a car do so (Blumenberg and Pierce, 2012; Brown, 2017, Chu, 2002, Giuliano and Dargay, 2006; Mitra and Saphores, 2017). Income may be the main factor, but the built environment, transit service, and land use policies all affect car ownership levels (Chatman, 2013; Guo, 2013; Salon, 2009; Weinberger, 2012, Zegras, 2010). The notable difference between car ownership in New York City and the rest of the U.S. is a case in point (King et al., 2019). The U.S. is an outlier when it comes to car ownership (Jones, 2008) but is not unique in having car-dependent areas or populations (Jeekel, 2016).

Low-income households likely want cars for many of the same reasons that more affluent households want cars: to participate in economic and social life (Blumenberg and Smart, 2011; Currie and Delbosc, 2011). Having a car provides greater access to jobs and other opportunities in a shorter time and permits more flexibility in travel compared with transit in almost all neighborhoods (Grengs et al., 2010; Kawabata and Shen, 2007, Shen, 2001; Liao et al., 2020). A large body of research, mostly in the U.S., has examined the relationship between transportation and employment outcomes. A recent meta-analysis by Bastiaanssen et al. (2020) finds that car ownership is consistently associated with positive employment outcomes among economically and otherwise marginalized populations. Beyond employment outcomes, car ownership enables poor families to move to better neighborhoods (Jeon et al., 2018), reduces barriers to accessing healthcare (Syed et al., 2013), eases grocery shopping (Clifton, 2004; Widener, 2017), and allows children to participate in after-school activities that improve their economic outcomes later in life (Ralph, 2018).

There are also reasons for low-income households to purchase cars that may not pertain to more affluent households. Households experiencing precarious employment and housing have an incentive to buy or keep a car to keep their jobs, retain social connections, and find new housing (Mullen and Marsden, 2018, Mullen et al., 2020). Low-income mothers may find public transportation too expensive and walking with children physically tiring and mentally stressful (Bostock, 2001). For those without cars, asking for rides and borrowing cars can be stressful, time-consuming, and strain relationships with family and neighbors (Murphy, forthcoming). 
But car ownership can also increase financial insecurity for low-income households. First, low-income households are more likely to experience financial risks when they purchase cars. When buying a car, low-income households have to navigate predatory car dealers and financing companies (Karger, 2003; Martin and Adams, 2012), and minority households face additional discrimination in the market (Ayres and Siegelman, 1995;| Rice and Schwartz, 2018). In the U.S., debt from car purchases has increased rapidly in the past decade (Cross et al., 2019), risks that fall disproportionately on those who live in auto-dependent neighborhoods (Lutz, 2014: Walks, 2018). However, those living in auto-oriented neighborhoods may have no choice but to obtain cars if they want to maintain their mobility. Researchers refer to low-income households living in such places as experiencing "forced car ownership" (Jones, 1987, Banister, 1994, Currie and Delbosc, 2013, Currie et al., 2018; Mattioli, 2017; Rock et al., 2016). Recent research from Glasgow and Melbourne suggests that forced car ownership is increasing (Curl et al., 2018: Currie et al. 2018).

Once they have cars, many low-income households struggle to maintain and keep them. In the U.K., two-thirds of carowning households in poverty experience "car-related economic stress," meaning that they spend a disproportionately high share of their income to use and maintain their cars (Mattioli et al., 2018). Further, in their study of forced car ownership in Glasgow, Curl et al. (2018) suggest that "rather than being forced into car ownership, the majority of respondents felt unable to give up a car despite experiencing financial difficulties" (p. 68 emphasis in the original). At the same time, these households' grip on car ownership is tenuous: Mattioli (2017) finds that almost every household in the U.K. and Germany experiencing forced car ownership would also be "unable to face unexpected financial expenses" ( $\mathrm{p} 156$ ). These households are further financially vulnerable to oil price volatility (Sipe and Dodson, 2013, Dodson and Sipe, 2007, Mattioli et al. 2019; Leung et al. 2018). Low-income households use a variety of strategies to reduce transportation costs while maintaining their mobility: forgoing trips, carpooling, repairing cars themselves, cutting back on other spending to keep using cars, skipping insurance and other fees, and searching for deals on gas, insurance, and parking (Blumenberg et al., 2018, Blumenberg and Agrawal, 2014; Brobeck and Hunter, 2012, Belton Chevallier et al. 2018; Froud et al. [2005, Fletcher et al. 2010;, Taylor et al. 2009).

Car-related expenses, chiefly repairs, are a common source of financial shocks for American households. These economic shocks are expenses that are unexpected and out of the households' control. One analysis of financial spending found that half of U.S. households spent at least $\$ 100$ on car repairs during one month in the past year, and ten percent had a car breakdown costing at least $\$ 700$ (Morduch and Schneider. 2017). Another survey found that $60 \%$ of U.S. households experienced a financial shock in the past year, with car repair or replacement being the most common type, affecting 30\% of households (The Pew Charitable Trusts, 2015). Fewer than 40\% of U.S. households have sufficient savings to weather an unexpected $\$ 400$ expense (Federal Reserve Board 2019). For low-income households, economic shocks "can result in a cascade of events that throws a low-income family into poverty" (Halpern-Meekin et al., 2018; Tach et al., 2018).

Consequently, low-income households in the U.S. transition into and out of car ownership much more often than affluent households (Klein and Smart, 2017). Changes in car ownership usually coincide with another significant life event, such as forming a couple, breaking up, having a child, gaining or losing a job, or moving (Clark et al. 2015; Prillwitz et al. 2006; Rau and Manton, 2016; Schneider and Ingram, 1993). Among low-income households, these life events play a smaller role in car ownership transitions, compared with more affluent households, suggesting that other factors play a larger role in low-income families' car ownership changes (Klein and Smart, 2019).

Using crowdfunding campaigns for personal cars on the site GoFundMe.com has the potential to provide new insights into the struggles associated with owning and maintaining cars in the U.S. Transportation researchers have used new online data sources to analyze transportation phenomena, though we are not aware of research using GoFundMe or analyzing car ownership. Schweitzer (2014) used Twitter data to examine sentiments about public transit in the U.S. Others have used Yelp data to examine non-work travel, trip planning, perceptions of transit stations, and parking supply (Mondschein, 2015; Bou Mjahed et al., 2017; Shin, 2019). To date, transportation researchers using these data sources have examined neither questions of car ownership nor the precarious nature of car ownership among low-income households.

\section{GoFundMe}

We use online appeals for crowdfunding for personal cars on the site GoFundMe.com to provide new insights into the struggles associated with owning and maintaining cars in the U.S. GoFundMe has been used to raise more than five billion dollars for over two million fundraising campaigns since its founding in 2010 (Heller 2019). While crowdfunding is not new, it is now more accessible and widespread. Campaigns on GoFundMe are personal fundraising efforts for specific causes, distinguishing it from other crowdsourcing websites that seek funding for a project or company (e.g., Kickstarter and Indiegogo) or civic projects (such as ioby and Patronicity). GoFundMe campaigns cover a diverse array of causes, with medical campaigns accounting for the largest category and for one-third of all the money raised on the 
site in 2017 (Heller 2019). The pervasiveness of medical crowdfunding in the U.S. reflects the lack of adequate and affordable healthcare and the growth of online crowdfunding (Berliner and Kenworthy. 2017). Although there are no published data on the number of car-related campaigns on the site, GoFundMe recently added a short article focused on accessing funds for car repairs. This article includes information about car repair costs, resources for people in need, and tips on using crowdfunding to raise money for car repairs (GoFundMe.com, 2019).

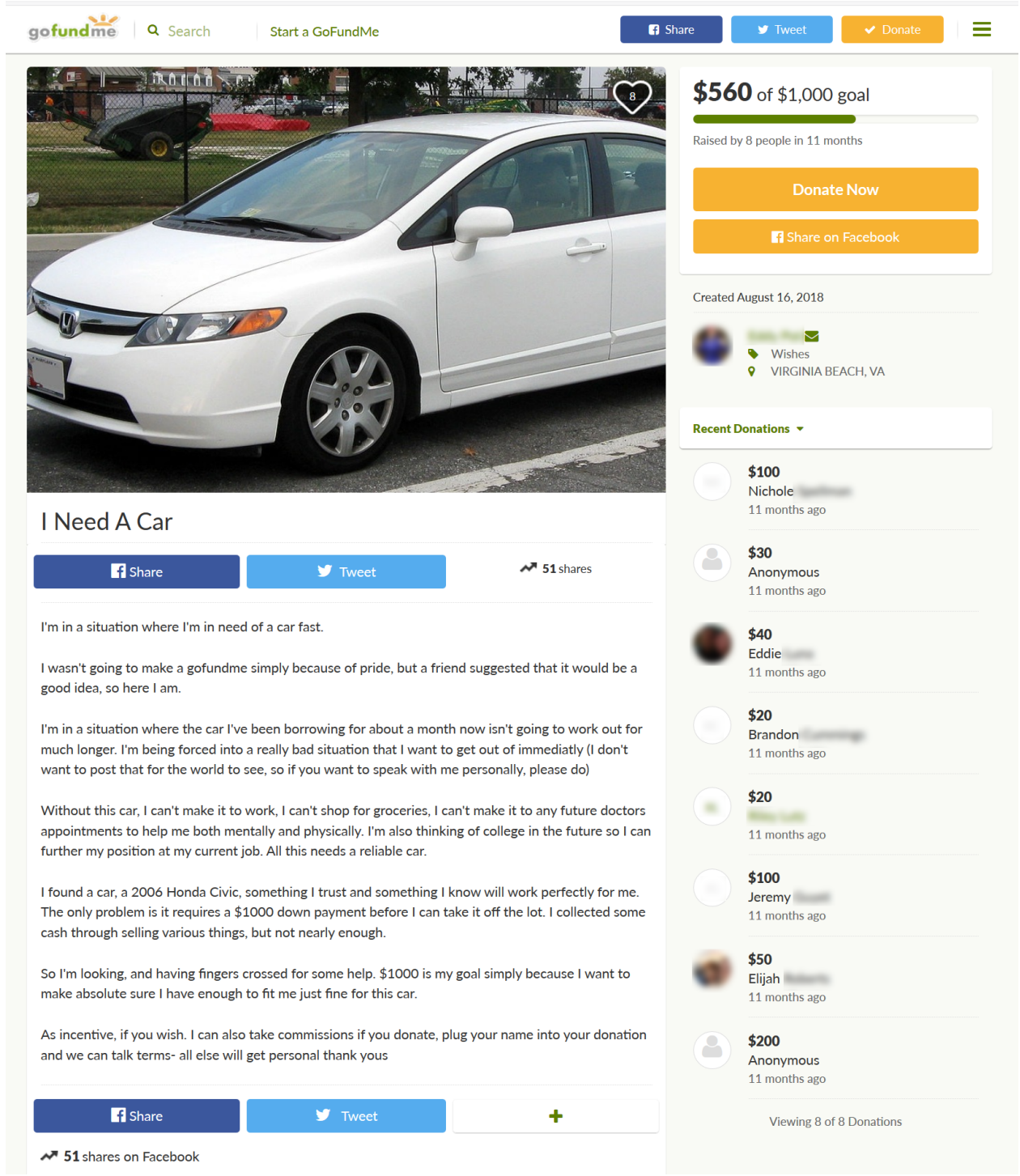

Figure 1: Example GoFundMe campaign for a car purchase (identifying information obscured)

Each campaign has a unique webpage that includes a title, narrative description of the campaign, funding goal, and amount raised to date (Figure 1 is an example). We refer to the author, initiator, or creator of the GoFundMe page as the "campaigner." Once a campaign is active, it remains online and accepting donations until the user deactivates the page. Unlike some crowdfunding platforms, GoFundMe users receive their donations regardless of whether the total contributions meet their stated goal. The company takes 30 cents per donation, along with a $2.9 \%$ transaction fee.

Users can create and publish a campaign in minutes on GoFundMe. During the process of setting up a solicitation page, GoFundMe offers suggestions to increase funding. Campaigners are strongly encouraged to publicize their campaign on social media and link to their Facebook page so that donors can verify who is raising funds. GoFundMe also recommends a narrative structure for the main body of the campaign. These narrative explanations vary by campaign category, but suggestions include: "explain what happened," "detail what the funds will be used for," "talk about what the support will mean to you," and "share how grateful you will be for help." Underlying GoFundMe's advice, Berliner 
and Kenworthy (2017) p. 239), note, is the fact that "the reality of the financial burden and attendant structural issues is shrouded in optimism and a disavowal of overwhelming need in favor of discrete and marketable requests."

Research on medical crowdfunding using GoFundMe suggests that these platforms may reproduce social inequalities. Crowdfunding can influence who and what medical conditions are deemed worthy of funding (Barcelos, 2019; Snyder. 2016, Berliner and Kenworthy, 2017). Rather than allocating healthcare based on medical need, medical care from crowdfunding allocates based on the "personal appeal, sensationalism, one's social position, or luck ... reward[ing] those already in a privileged position" (Snyder, 2016, p. 38). Crowdfunding sites also focus attention on individuals and their perceived deservingness and away from systematic problems with the healthcare system (Snyder et al. 2016). People of color, particularly black women, are underrepresented in medical campaigns on GoFundMe relative to the U.S. population, and black campaigners receive, on average, less money than white campaigners (Kenworthy et al. 2020). Campaigners can also signal themselves as worthy of support and deserving of financial assistance by framing an appeal as an anomaly and as a last resort, portraying themselves as self-sufficient, explaining their willingness to work, and demonstrating how the money will be used (Radu and McManus, 2018;, Paulus and Roberts, 2018). Medical crowdfunding also raises questions about fraudulent or embellished narratives and the monetization by crowdfunding businesses of unmet medical needs (Snyder. 2016, Snyder et al., 2016).

\section{Data and Methods}

To analyze GoFundMe campaigns, we scraped the GoFundMe.com website in July 2019. First, we identified a set of search terms that we could use to target relevant campaigns on the site: "need car," "car repair," "replace car," "buy car," "stolen car," "fix car," "car trouble," and "broke car." Next, we used the Python library Selenium to generate a list of GoFundMe campaign URLs that came up when searched on the GoFundMe.com website. We then used Python library Beautiful Soup to scrape each of these 1,028 GoFundMe campaigns. For each campaign page, we saved the campaign title, location, date created, campaign goal, amount raised, number of donors, and campaign narrative.

We manually removed campaigns that were not relevant to our research and categorized those that remained. We first excluded 287 campaigns whose primary purpose was not related to a car, leaving 741 campaigns. For example, some of these campaigns centered on raising money for medical care but happened to mention a car. We then excluded 170 campaigns based outside the United States, 120 created before 2018, and then 116 campaigns that had not received any donations at the time we collected the data (though these may have received donations later). We manually categorized campaigns as focusing on a car purchase, car repair, or some other purpose (e.g., car payments or insurance). Our final sample included 335 campaigns. The median narrative was 150 words, ranging from a perfunctory eight-word description ("Donations for my birthday will be accepted thanks.") to 1,271 words.

We analyzed the campaigns using both quantitative text mining techniques and qualitative analysis. We first analyzed GoFundMe campaign narratives using text mining tools (the TidyText package in R) as an initial exploratory tool to examine word frequency and pairing (Silge and Robinson, 2017). We then coded each campaign for the campaigner or campaign recipient's (in the case where someone was campaigning on behalf of another person) demographic attributes based on contextual clues in the campaign narratives or other data. Informed by Kenworthy et al. (2020), we coded perceived gender, life-cycle (young adult, adult, older adult), and single-parent status, when the information was present in the narratives. For campaigns on behalf of mixed-gender couples, we coded the campaign as such. We did not code a perceived race/ethnicity of campaigners, because we did not scrape campaign photos or feel confident that we could code race/ethnicity through other information.

We then imported the 335 campaign narratives into qualitative analysis software (MAXQDA version 2020). We began our coding process focusing on the two broad themes: understanding why campaigners wanted a car (motivation) and, for those who were replacing or repairing a car, what happened to that car (precipitating events). During our coding process, we added detailed codes within each broad category (e.g., wanting a car to chauffeur children) and codes that we had not anticipated before coding (e.g., campaigner's multiple background factors or struggles). Each narrative was coded at least twice by two of the three authors.

There are several limitations to using GoFundMe narratives for research. The campaigns we analyzed are a nonrepresentative sample. Users of the site have self-selected to create a campaign and may differ from others experiencing precarious car ownership. Campaigners may skew younger than carless households in the U.S. since GoFundMe is an online platform, and young people tend to be more familiar and savvier with new technology.

Our sample is also not representative of GoFundMe campaigns. Our sample reflects the keywords we entered in the search, the GoFundMe search algorithm, and the exclusions we chose. The keywords we selected to identify campaigns for car purchases and repairs may unintentionally skew our results. Our search results may reflect algorithmic bias in 
the search (Noble, 2018). Further, we introduce additional bias by limiting our analysis to campaigns that received at least one donation as a way to exclude campaigns started as a lark.

We have limited information about campaigners and did not verify the narratives. We are limited to what people write in their campaign description and know nothing about other factors in their lives that may influence their car ownership. We also cannot verify the validity of narratives (Radu and McManus. 2018). And the narratives may be biased by what campaigners believe will generate funding rather than their actual motivations or circumstances Snyder et al. (2016); Snyder (2016). For example, one could imagine copycat GoFundMe pleas after the successful funding for James Robertson (described in the opening paragraph). Others may omit details that they believe would inhibit donations or may include false details they think will generate funding.

\section{Results}

The following summarizes our sample and our findings. We first describe our sample, focusing on the characteristics of the campaigns and campaigners. We then present our findings using text mining approaches. Finally, we present our findings from our qualitative analysis of the campaign narratives.

\subsection{Campaigns and campaigners}

Our final sample for analysis includes 335 campaigns - 226 campaigns for car purchases, 78 for repairs, and 31 for other purposes-summarized in Table 1. The median campaign goal (amount requested) was $\$ 2,000$ in the full sample, $\$ 2,500$ among those seeking to purchase a car, and $\$ 1,500$ among those looking to fund a repair. The median campaign raised $\$ 200$, with campaigns for car purchases receiving slightly more (\$220) than those seeking money for repairs (\$208). While only 19 campaigns (5.6\%) achieved or met their stated goal, campaigners receive the full amount pledged. The median number of individual donations campaigns received was 4 , and the maximum was 105 donations.

Table 1: Summary of GoFundMe Campaigns ( $\mathrm{N}=335)$

\begin{tabular}{llllll}
\hline & $\mathbf{N}$ & Min & Median & Mean & \\
\hline Full sample & & & & & \\
Campaign goal & 335 & $\$ 150$ & $\$ 2,000$ & $\$ 3,402$ & $\$ 40,000$ \\
Amount raised & 335 & $\$ 5$ & $\$ 200$ & $\$ 513$ & $\$ 7,206$ \\
Number of donations & 335 & 1 & 4 & 7.4 & 105 \\
\hline Campaigns for car purchase & & & & & \\
Campaign goal & 226 & $\$ 150$ & $\$ 2,500$ & $\$ 3,868$ & $\$ 40,000$ \\
Amount raised & 226 & $\$ 5$ & $\$ 220$ & $\$ 585$ & $\$ 7,206$ \\
Number of donations & 276 & 1 & 4 & 8 & 105 \\
\hline Campaigns for car repair & & & & & \\
Campaign goal & 78 & $\$ 160$ & $\$ 1,500$ & $\$ 2,323$ & $\$ 20,000$ \\
Amount raised & 78 & $\$ 5$ & $\$ 208$ & $\$ 397$ & $\$ 2,838$ \\
Number of donations & 78 & 1 & 4 & 6.7 & 71 \\
\hline Other campaigns & & & & & \\
Campaign goal & 31 & $\$ 260$ & $\$ 1,500$ & $\$ 2,724$ & $\$ 15,000$ \\
Amount raised & 31 & $\$ 15$ & $\$ 120$ & $\$ 275$ & $\$ 1,110$ \\
Number of donations & 31 & 1 & 3 & 5.2 & 22 \\
\hline
\end{tabular}

We find that women and single parents disproportionately use GoFundMe to crowdfund car repairs and purchases (Table 2). We coded $95 \%$ of the campaigns with a perceived gender based on self-identification, pronoun use, names, and other contextual information. We classified $58 \%$ of the campaigns as intended for women, $28 \%$ for men, $13 \%$ for mixed-gender couples, and one campaign for a nonbinary recipient. We identified $13 \%$ of the campaigns intended for young adults (identified if they indicated that they were in high school, college, or younger than 26 years old) and 5\% for older adults. Finally, 19\% (63) of the campaigns identified the recipients as a single parent, all but five of which we coded as women. That women and single-mothers use GoFundMe at high rates to crowdsource car funding may reflect that these groups have limited financial resources to purchase cars yet they stand to benefit the most when they have them (Blumenberg, 2016).

Campaign locations align with U.S. population distribution. Figure 2 maps the number of campaigns by state, and we find that the count of campaigns is highly correlated with the 2018 state population $(r=0.93)$. The three states with the 
highest population, California (40), Texas (29), and Florida (28), have the most campaigns, while locations with the smallest populations, Wyoming (0), Vermont (1), and Washington, DC (1), have among the fewest.

Table 2: Demographics of campaigner or recipient $(\mathrm{N}=335)$

\begin{tabular}{lll}
\hline & Count & Share \\
\hline Gender & & \\
Female & 187 & $56 \%$ \\
Male & 90 & $27 \%$ \\
Mixed-gender couple & 42 & $13 \%$ \\
Nonbinary & 1 & $0.30 \%$ \\
N.A. & 15 & $4 \%$ \\
\hline Age & & \\
Young adult & 43 & $13 \%$ \\
Older adult & 17 & $5 \%$ \\
Other/NA & 275 & $82 \%$ \\
\hline Single-parent & & \\
Female single-parent & 58 & $17 \%$ \\
Male single-parent & 5 & $1 \%$ \\
Other/NA & 272 & $81 \%$ \\
\hline Geography & & \\
Urban & 97 & $29 \%$ \\
Suburban & 199 & $59 \%$ \\
Rural & 39 & $12 \%$ \\
\hline
\end{tabular}

We also find that most campaigns are in suburban areas. The share of campaigns in suburban areas is only slightly higher than the share of the U.S. population residing in these areas and closely matches rates of car ownership in the U.S. among households in urban, suburban, and rural counties. We geocoded the campaign locations and used the National Center for Health Statistics (NCHS) Urban-Rural Classification Scheme for Counties to assign locations to urban, suburban, and rural areas ${ }^{2}$. We find that $59 \%$ of campaigns are in suburban areas compared with $55 \%$ of the U.S. population (U.S. Census Bureau 2019). Twenty-nine percent of campaigns are in urban counties and $12 \%$ in rural areas (compared with $31 \%$ and $14 \%$ of the U.S. population). By comparison, 30\% of car-owning households are in urban, $60 \%$ are in suburban, and 10\% are in rural counties (U.S. Census Bureau, 2019).

\subsection{Text Mining}

We used text mining tools to analyze the frequency of and relationship among words in campaign titles and narratives. The 335 campaign narratives consisted of 19,099 total words and 4,423 unique words after removing common stop words (e.g., "the," "to," and "a"). The most frequently used word in the campaign narratives is "car" (used 836 times). After that, the frequency drops off quickly: time (215), money (210), family (171), vehicle (170), job (144), school (129), life (124), mom (95), and home (93).

We also used text mining tools to analyze how words are paired to provide context to the frequency tables. Analyzing pairings allows us to distinguish between the different uses of a word and to begin to examine the context in which these words are used. Figures 3 and 4 are directional graphs for all the word pairs (bigrams) occurring five or more times in titles and campaign narratives. The arrows indicate the order (e.g., the arrow points from "car" to "insurance," indicating that the word pair is "car insurance").

The campaign title graph (Figure 2) succinctly captures the urgency in these campaigns. People seeking funding on GoFundMe desperately need a car. The quote we use in the title of this article comes from one such campaign title, though variations on this theme were common in the campaigns. Nineteen campaign titles (6\%) used the word "desperate" or "desperately" in some variation of the title for this article. Campaign titles that used the combination of "single mom" or "single mother" were also common, appearing in 35 campaigns. Campaign titles included "mom" and "mother" in an additional 16 campaigns.

\footnotetext{
${ }^{2}$ The NCHS Urban-Rural Classification uses six categories, which we reduced to three. We classified large central metro counties as urban; fringe metro counties, medium metros, and small metros as suburban; and micropolitan and non-core counties as rural.
} 


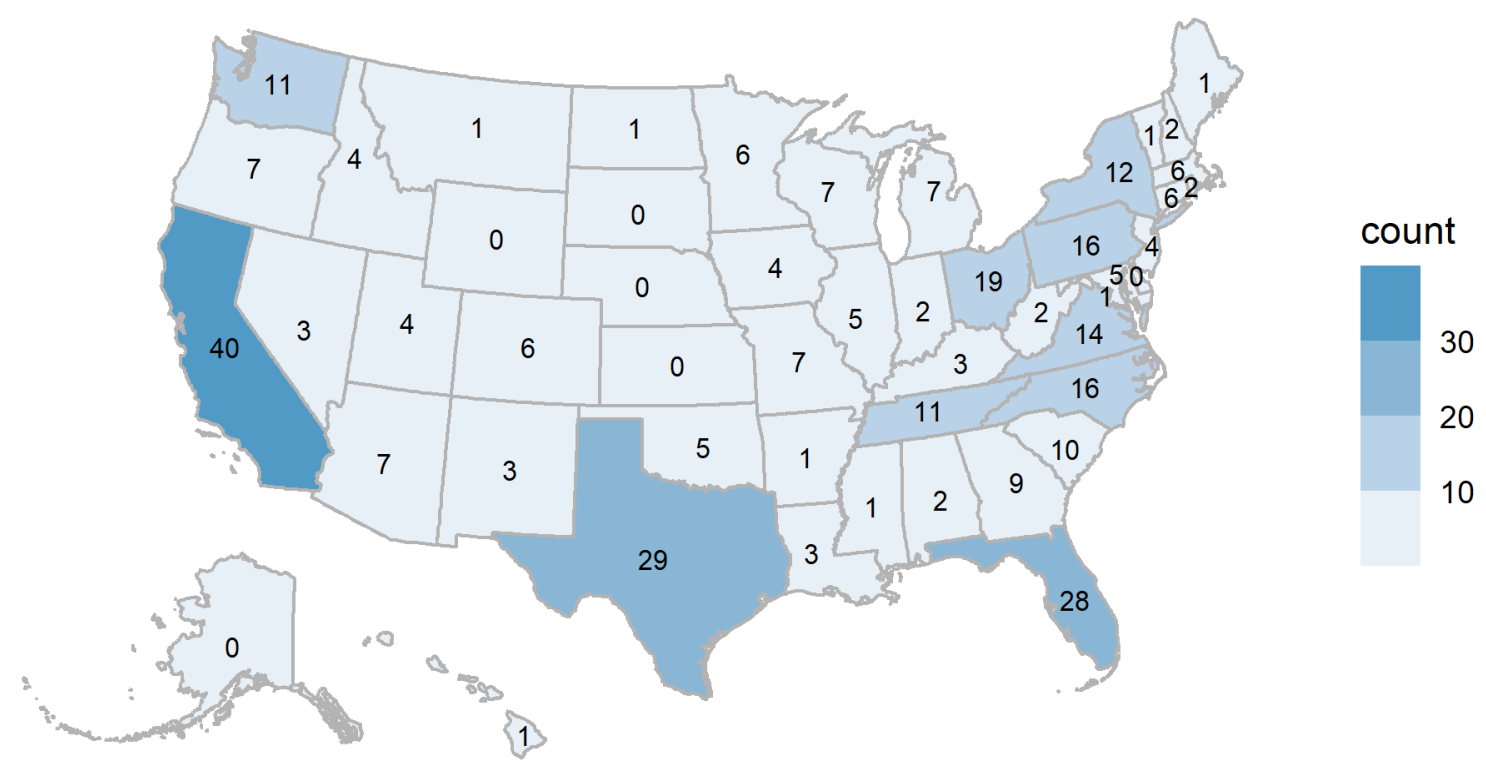

Figure 2: Campaigns by State in the US $(\mathrm{N}=325)$

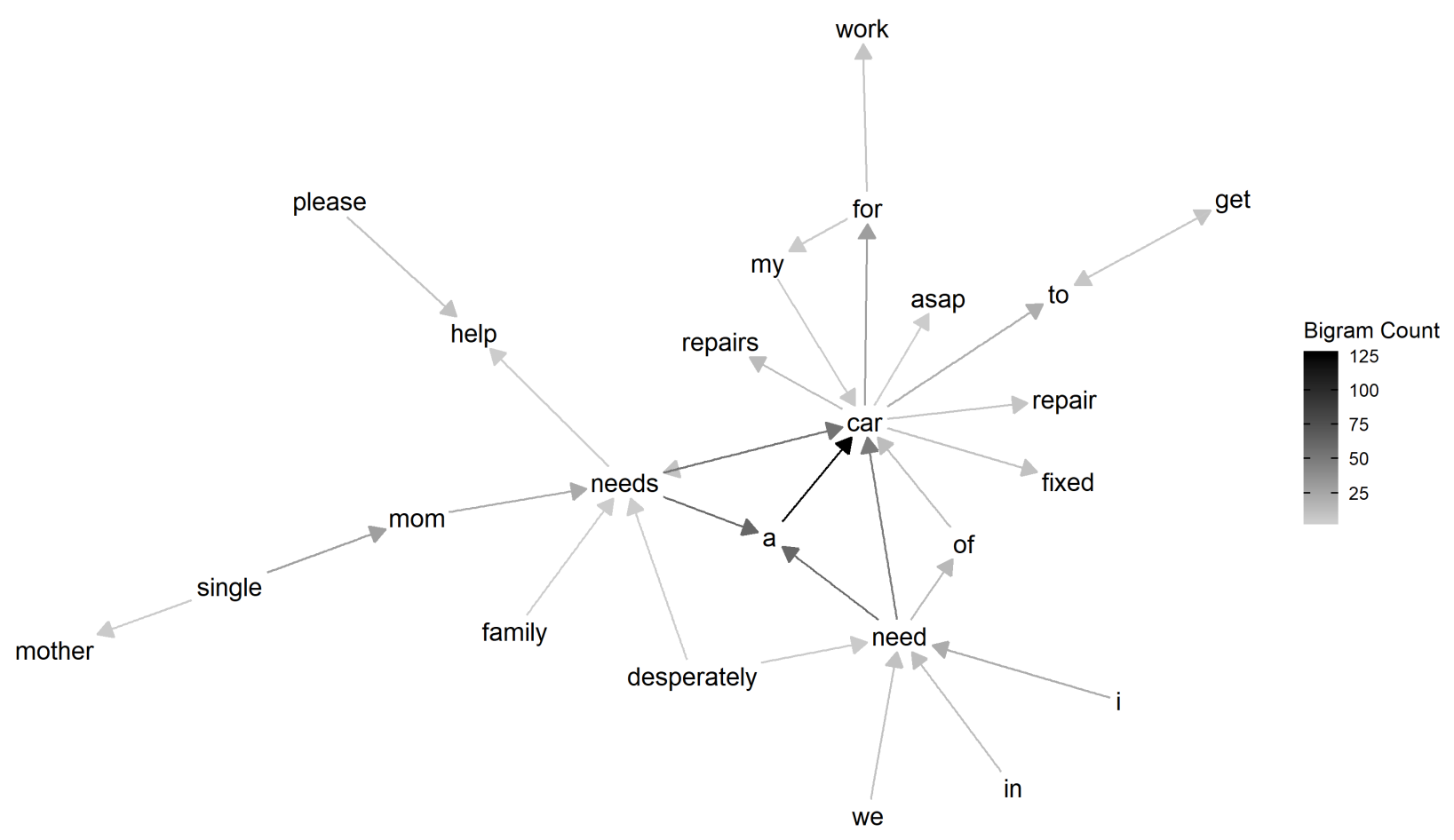

Figure 3: GoFundMe campaign title word pairs (occurring at least five times) 
In the campaign narrative graph (Figure 3), the most prominent cluster of interrelated words surrounds the word "car." This cluster suggests that car troubles ("car accident," "car broke," and "car died") and needs ("reliable car/transportation" "car payment," "car repairs," and "car seat") are at the heart of GoFundMe campaigns. Other transportation-related bigrams point to how the car will be used ("delivery driver"), alternatives to driving ("public transportation"), and destinations ("grocery store," "doctor appointments," "community college"). Notably, work travel does not appear prominently in the graph despite being the sixth most commonly used words in campaign narratives. Finally, the bigram analysis also suggests themes of financial insecurity, health, childcare, household structure, and schooling are all evident in the GoFundMe campaign narratives.

The text analysis paints a picture of campaigners experiencing both car difficulties and other challenges in their lives. In the following section, we use qualitative analysis to examine the campaign narratives in more depth.

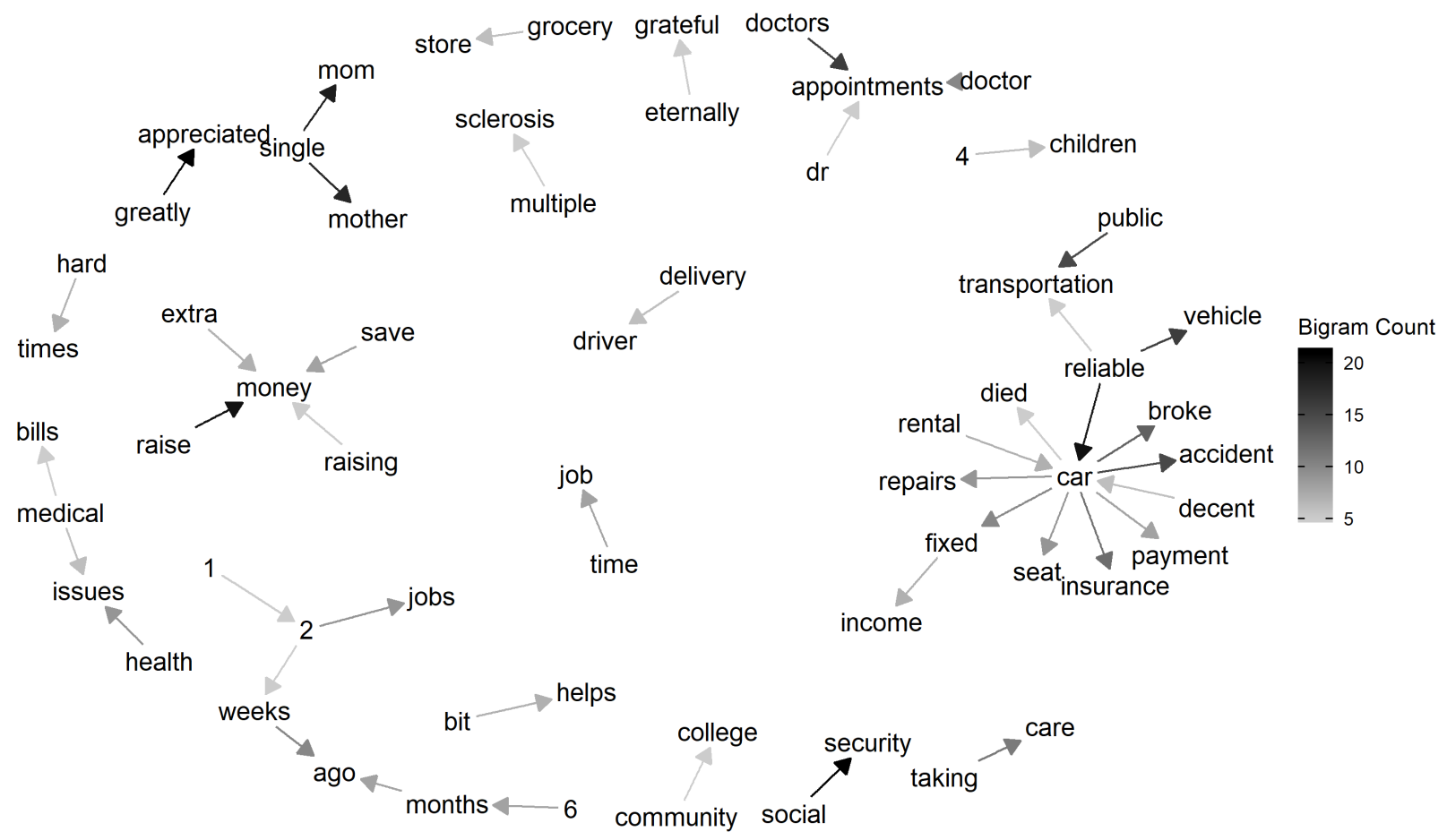

Figure 4: GoFundMe campaign narrative word pairs (occurring at least five times)

\subsection{Analysis of Campaign Narratives}

The following describes our qualitative analysis of the GoFundMe campaigns. We first explain campaigners' motivations for having a car. Next, we describe the precipitating events that led them to GoFundMe. Finally, we outline the broader context and framing that the campaigns used in their pleas for funds to repair or purchase a car.

\subsubsection{Why they wanted cars}

In their GoFundMe narratives, campaigners most often described wanting to purchase or repair a car so that they could travel to and from work, school, and medical care, and could chauffeur their children. In many cases, they contextualized these needs by saying that other transportation options did not exist, were too limited, or were too expensive. Fewer campaigns mentioned wanting a car for reasons of personal safety and well-being. Table 3 summarizes the stated reasons campaigners wanted a car.

The most commonly stated motivation for wanting a car was to get to and from work. Forty-six percent of campaign narratives (154 campaigns) specifically mentioned travel to and from work. These campaigns described wanting or needing a car to get to and from work as well as how not having a car was affecting their employment, job performance, earnings, and household finances. Seven campaigns mentioned needing a car to start a new job, and another mentioned needing a car to look for employment. Seventeen of the campaigns mentioned needing a car to work as a rideshare 
driver or delivery worker, or because their work location varied (e.g., a house cleaner). As one campaigner explained, "I need this car not just for daily commute to my retail job, but I also deliver groceries and meals as a second job, and I desperately need my car for this."

Many of the campaign narratives highlight the economic consequences of losing access to a car. The focus on the effects of losing cars contrasts with the literature on economic outcomes associated with car access, which focuses more on the effects of having or gaining a car (Bastiaanssen et al. 2020). For example, one campaigner wrote, "I have lost my job... Not having a car has crippled me from working to pay my rent and bills." Another wrote, "Haven't been able to work since last week without a working car since job is 45 minutes away. Need car fixed ASAP to continue employment and support our family!"

Table 3: Motivation for wanting a car $(\mathrm{N}=335)$

\begin{tabular}{llll}
\hline Motivation & Count & Share & Share with motivation \\
\hline Work travel & 154 & $46 \%$ & $60 \%$ \\
Accessing medical care & 88 & $26 \%$ & $34 \%$ \\
Chauffeuring children & 54 & $16 \%$ & $21 \%$ \\
Transportation challenges & 44 & $13 \%$ & $17 \%$ \\
School travel & 40 & $12 \%$ & $16 \%$ \\
Limited or no public transportation & 27 & $8 \%$ & $11 \%$ \\
Shopping & 24 & $7 \%$ & $9 \%$ \\
Family/social travel & 17 & $5 \%$ & $7 \%$ \\
Other activities & 8 & $2 \%$ & $3 \%$ \\
Personal safety & 7 & $2 \%$ & $3 \%$ \\
\hline Total campaigns with a motivation & 256 & $76 \%$ & $100 \%$ \\
Campaigns with no motivation & 79 & $24 \%$ & \\
\hline Total & $\mathbf{3 3 5}$ & $\mathbf{1 0 0 \%}$ \\
\hline
\end{tabular}

After work travel, the most commonly mentioned travel purposes were medical (88 campaigns), chauffeuring children (54 campaigns), school (40 campaigns), and shopping (25 campaigns). The frequency of medical travel in these campaigns may be related to GoFundMe as a popular site to raise money for medical care (Snyder et al. 2016).

Among those mentioning medical travel, campaigners wrote about chronic illness or other conditions that require frequent medical appointments and mobility restrictions that make travel on transit difficult (e.g., wheelchairs or oxygen tanks). These campaigns suggested that a lack of reliable transportation led to missed and delayed medical care (see also Syed et al. 2013). For example, a campaign for Stephanie (name changed) appealed for funds to repair her car:

"Stephanie recently had knee replacement surgery and is recovering appropriately, but she struggles to do some of the things she once enjoyed... Stephanie has frequently cancelled or had to re-schedule her medical appointments because her car would not start. Depression often causes her to confine herself to her apartment, rather than to interact with her friends and family."

Campaign narratives also suggest that many campaigners live in places with limited public transit or face other transportation challenges. Twenty-seven campaigns (8\%) indicated that there was no public transit where they lived, that the location had limited public transit coverage, frequency, or hours of operation, or that commuting via public transit would take a very long time. These descriptions of transit were usually short and to the point: “... I live in a place where public transportation is not good." In a few cases, the campaigns made explicit the connection between the lack of public transit where they lived and high transportation expenses:

"To get around now my kids and I walk to the store to get what we need because there is no public transportation in our County. I have to pay for rides to get to work on a daily basis. So the little that I make at work, I spend half of it to pay to get to work."

Another 44 campaigns described transportation challenges (beyond a lack of public transportation) that campaigners faced without a working car: walking long distances, high costs for other travel options, borrowing cars or asking for rides, and renting cars.

Safety and personal well-being were other motivations for seeking crowdfunding. In some cases, personal well-being was manifest in the campaigns in a desire to spend more time with their family, for less onerous travel, or to feel connected and integrated with their community. But in seven campaigns, for queer, trans, and homeless individuals and 
domestic violence survivors, personal safety was prominent in their narratives. These cases include people who were carless after leaving unsafe relationships and people who felt unsafe traveling.

\subsubsection{Precipitating events}

The most common reason GoFundMe campaigners were without a working car was an unexpected event combined with financial insecurity. Table 4 summarizes our analysis of the campaign narratives to understand what events precipitated the campaigns. We considered cars that broke down or needed repairs (136), crashed (50), and were stolen (8) as unexpected events. Together, these events accounted for $58 \%$ of the campaigns and $78 \%$ of the campaigns that listed an event. A typical campaign described a car breaking down on a highway, such as this one:

"I was driving on the highway when my check engine light came on ... That's when my car started slowing down to a stop and a bit [sic] white puff of smoke came out from under the hood."

That unexpected events often result in losing access to a car suggests that many households experiencing forced car ownership have a precarious grasp on car ownership. In the U.K. and Germany, Mattioli (2017) found that 97\% of households experiencing forced car ownership could not meet an unexpected financial need. For more affluent households, an unexpected event like a breakdown might not lead to an episode of carlessness. But for the campaigns we analyzed, the households do not have financial reserves and are at risk of losing their car.

Table 4: Precipitating events for crowdfunding campaigns

\begin{tabular}{llll}
\hline Event & Count & Share & Share with event \\
\hline Breakdown or needed repairs & 136 & $41 \%$ & $55 \%$ \\
Crash & 50 & $15 \%$ & $20 \%$ \\
Unreliable & 24 & $7 \%$ & $10 \%$ \\
Repossession & 12 & $4 \%$ & $5 \%$ \\
Car payments & 10 & $3 \%$ & $4 \%$ \\
Stolen & 8 & $2 \%$ & $3 \%$ \\
Other & 8 & $2 \%$ & $3 \%$ \\
\hline Total campaigns with an event & 248 & $74 \%$ & $100 \%$ \\
Campaigns with no event & 87 & $26 \%$ & \\
\hline Total & $\mathbf{3 3 5}$ & $\mathbf{1 0 0 \%}$ & \\
\hline
\end{tabular}

We also categorized 24 campaigns raising money to replace an unreliable vehicle. These campaigners owned cars but could not depend on them because they were so unreliable (similar to descriptions of "vehicle fitness" in Lovejoy and Handy, 2008). One campaign, on behalf of an acquaintance, wrote, "She has a car that has had numerous mechanical repairs and replacements, but which constantly breaks down, sometimes while she is on the road!" Not only were the cars unreliable, but they were expensive to own and maintain. As one campaigner put it, "I currently have a car that I"ve dumped thousands into and I constantly get left stranded."

Unreliable cars and unexpected events are two sides of the same coin. Many campaign narratives characterized their cars as unreliable and noted how they often broke down or that they needed frequent repairs. Low-income households are more likely to purchase older and less expensive cars, which require more maintenance. Campaigns often characterized the cars as older (15 or more years old) with high mileage (150,000 or more miles). For example, one campaign cited "an ancient minivan with more than $250 \mathrm{~K}$ miles that needs constant repair." In their analysis of working families' spending, Morduch and Schneider 2017, p. 55 describe these types of "economic shocks," noting, "The size and the timing of repairs are unpredictable, but the fact of their eventual occurrence is not."

We classified $22(7 \%)$ campaigns with repossession or other car payments as the precipitating events. These campaigns included campaigns to purchase a new car following a repossession, to recover a repossessed car, or to pay car loans, registration charges, insurance premiums, and towing fees. The automobile debt suggested in these campaigns is indicative of a type of transport disadvantage, one that is more likely to affect those in auto-dependent areas (Walks, 2018). When describing car repossession, campaign narratives often noted related events, such as a job loss, illness or medical expenses, and housing insecurity. These descriptions echo (Tach et al. 2018, p. 281), who find that financial shocks and insecurity "cascaded across categories, amplifying their consequences." Cascading events were evident among many campaigns, but more common among those experiencing car repossessions. One campaigner described how "unexpected expenses" led to repossession of their car, missing work, and falling behind on their housing payments: 
"Like all of us who are living paycheck to paycheck, emergencies and unexpected expenses came up and the money I was making for my car had to go to our rent. Now our January rent is past due and my car was repossessed for nonpayment earlier this week. My brother has missed several days of work and is on the verge of losing his job. His next (and possibly final if we don't find a solution fast) paycheck has to go to pay rent, but he also needs that money to get a rental car and/or save towards the purchase of a used car. It's the proverbial rock and a hard place."

The eight campaigns we classified as having "other" precipitating events described family changes, breakups, a divorce, or leaving home, some of which specified leaving an abusive residence or relationship.

Twenty-six percent of campaigns did not describe what happened to their previous or current car. The fact that most campaigners experienced car ownership before is likely a reflection of most U.S. residents, even most low-income residents, own cars (Blumenberg and Pierce, 2012, King et al. 2019).

\subsubsection{The broader context}

Many of the GoFundMe campaign narratives presented the campaigner's transportation challenges in the context of additional struggles in their lives. For these campaigners, not having a functioning car was one of several interrelated challenges, complications, or crises. We coded 126 campaigns (38\%) as indicating multiple factors accompanying the campaigner's car troubles. In addition to not have access to a working car, these narratives mentioned one or more of the following: chronic or pressing medical conditions, taking care of someone with a medical condition, job loss, loss of a home or other housing crisis, loss of a family member, a breakup, or domestic abuse. Some found themselves stuck between becoming carless and falling behind on other bills: "So now I have to choose between fixing my car or paying rent for June." Campaigners also may have felt that setting up a GoFundMe site to raise money for a car rather than for rent was more socially acceptable or would position them as more deserving. Either way, not having a functioning car was part of a set of personal and financial struggles they and other GoFundMe campaigners faced.

Campaigners also framed their use of GoFundMe as a last resort while simultaneously describing themselves as hardworking, grateful, and resilient. This framing is consistent with previous research on GoFundMe campaigns (Paulus and Roberts, 2018, Radu and McManus, 2018) and social constructions of deservingness (Katz, 2013; Schneider and Ingram, 1993; Berliner and Kenworthy, 2017). For example, one campaigner, who identified herself as a "disabled veteran," a doubly deserving category, described her efforts to be self-reliant: "I have been struggling to do things on my own and not be a burden on anyone else, but now I am at a loss for how to best handle this, and so I come here to ask you, and others for help." Others focused on how they would use the car to get to and from work, to access medical care, to give back to society, to sustain themselves and their families, and to recover from crises outside of their control.

Campaigners also promised that they would make prudent use of the funds. Campaigners often used some variation on the idea that they were not looking to purchase a "fancy" car. In a typical example, a delivery worker associated financial responsibility with being a productive worker and good mother:

"I am not going for anything fancy just something reliable so not stranded and having to walk in the cold or put strain on my job. ... All I want is to be able to safely get to work so I can put in the hours to pay the bills and make sure my daughter is taken care of ... I just want to be a good mom and employee and be able to get where [I] need to go to get things done."

\section{Discussion}

Our findings contribute to understanding households' precarious grasp on car ownership. We find that in a majority of crowdfunding campaigns on GoFundMe for car purchase or repair, campaigners were without a functioning car because they could not afford to repair or replace a car after an unexpected event: a car that broke down, needed repairs, was in a crash, or was stolen. These findings help explain previous findings that low-income households go into and out of car ownership more often than affluent households and why life events have differential effects on gaining and losing access to a car for low-income and affluent families (Klein and Smart, 2017, 2019).

Research on economic shocks supports our findings. Car repairs are among the most common sources of economic shock for American households, and 39\% of Americans cannot cover an unplanned \$400 expense (The Pew Charitable Trusts, 2015; Federal Reserve Board, 2019). Additionally, research on households experiencing forced car ownership shows that they likely risk losing their vehicle if they experience an unexpected financial shock (Mattioli, 2017). Although our results are most applicable to the U.S., we expect these findings apply to other contexts where households face forced car ownership. 
The crowdfunding campaign narratives also revealed that not having a functioning car was often part of a broader set of personal and financial struggles in campaigners' lives. More than one-third of the campaign narratives described financial, medical, and personal crises. Not having a functioning car and the costs of repair or replacement compounded challenges in the campaigners' lives. The campaign narratives provide further evidence that the economic shocks associated with car loss or car repair intertwine with other financial challenges, job loss, healthcare needs, and housing insecurity (Halpern-Meekin et al. 2018; Tach et al. 2018). We note here that the importance of access to healthcare and medical needs in campaign narratives is likely not generalizable outside the U.S.

Appeals for funding for car repair and purchase often evoked campaigners' deservingness of a car to get to work, go to school, receive and provide medical care, chauffeur children, and go shopping. These campaigns situated unexpected events in the context of people's deservingness as hardworking, grateful, and resilient individuals. Car crashes, illnesses, and employment gaps are intricately linked to the loss of a car or need for repair. But as others have found with medical crowdfunding (Snyder et al. 2016), campaign narratives focused attention on the individuals' circumstances rather than the structural problems in society.

The GoFundMe campaign narratives also reinforce the image of car ownership as a necessity for many residents of the U.S. The majority of campaign recipients in our sample lived in suburbs and were disproportionately female, and single-parents, groups likely to benefit from access to cars more than others (Blumenberg, 2016). CCampaigners wanted cars to travel to and from work, school, and medical care, and chauffeur their children. Only 27 (8\%) campaign narratives mentioned public transportation. The remaining campaigns did not even mention public transportation, suggesting these campaigners perceive cars as the only viable transportation mode that can meet their needs. For most campaigners, the latter is likely the case given that having a car is an unfortunate necessity in most of the United States (King et al. 2019). As a result, maintaining a car might mean relying on the mercy of friends and strangers to pay for it. However, most car related crowdfunding campaigns do not meet their funding goals. The median campaign we analyzed raised only $\$ 200$, a tenth of the median fundraising goal.

We see several paths for future research based on our findings. First, future research should test whether gender, age, and race/ethnicity affect the amount of funds raised for car purchase or repair and the extent to which these factors affect campaign outcomes (Kenworthy et al. 2020, is a recent example analyzing medical crowdfunding). Second, research using surveys could examine the extent to which the precipitating events described in this analysis are representative of the reasons why low-income households lose access to car ownership. Finally, future research should examine the effects of losing access to a car for low-income households. Our findings, along with research on the finances of working families (Morduch and Schneider. 2017), suggest that the financial and mobility impacts of car loss can have significant negative consequences for households.

\section{Data Availability}

Data archived for this paper: Klein, N. J., Riley, S., \& Tran, M. (2019, December 10). "Desperately in Need of Car": Analyzing Crowdfunding Campaigns for Car Purchases and Repairs on Gofundme.com. http://osf.io/tmvgk

\section{Conflict of interest statement}

On behalf of all authors, the corresponding author states that there is no conflict of interest.

\section{Author contributions}

The authors confirm contribution to the paper as follows: N. Klein: Conceptualization, Methodology, Software, Formal Analysis, Investigation, Resources, Data Curation, Writing - Original Draft, Writing - Reviewing \& Editing, Visualization, Supervision, Project Administration. M. Tran: Formal Analysis, Investigation, Writing - Original Draft, Writing - Reviewing \& Editing. S. Riley: Conceptualization, Methodology, Software, Formal Analysis, Investigation, Writing - Reviewing \& Editing

\section{Acknowledgemenits}

Thanks to Cass (Z.) Wilkinson Saldaña for advice on data retrieval. Thanks also to Anne Brown, Michael O'Key, Matthew Palm, and anonymous reviewers from Travel Behaviour and Society and the Transportation Research Board standing committee on Social and Economic Factors provided additional comments. A version of this paper was 
presented at the Annual Meeting of the Transportation Research Board (TRB) in Washington DC in January 2020. Paper \#20-02266

\section{References}

Ayres, I. and Siegelman, P. (1995). Race and gender discrimination in bargaining for a new car. The American Economic Review, 85(3):304-321.

Banister, D. (1994). Equity and Acceptability Questions in Internalising the Social Costs of Transport. In Internalising the social costs of transport., pages 153-175. European Conference of Ministers of Transport, Organisation for Economic Co-operation and Development ; OECD Publications and Information Centre, Paris, France : Washington, D.C.

Barcelos, C. A. (2019). 'bye-bye boobies': normativity, deservingness and medicalisation in transgender medical crowdfunding. Culture, Health \& Sexuality, 0(0):1-15. PMID: 30762488.

Bastiaanssen, J., Johnson, D., and Lucas, K. (2020). Does transport help people to gain employment? A systematic review and meta-analysis of the empirical evidence. Transport Reviews, pages 1-22. Publisher: Informa UK Limited.

Belton Chevallier, L., Motte-Baumvol, B., Fol, S., and Jouffe, Y. (2018). Coping with the costs of car dependency: A system of expedients used by low-income households on the outskirts of Dijon and Paris. Transport Policy, 65:79-88.

Berliner, L. S. and Kenworthy, N. J. (2017). Producing a worthy illness: Personal crowdfunding amidst financial crisis. Social Science \& Medicine, 187:233-242.

Blumenberg, E. (2016). Why low-income women in the US still need automobiles. Town Planning Review, 87(5):525545.

Blumenberg, E. and Agrawal, A. W. (2014). Getting around when you're just getting by: Transportation survival strategies of the poor. Journal of Poverty, 18(4):355-378.

Blumenberg, E., Brown, A., and Schouten, A. (2018). Car-deficit households: determinants and implications for household travel in the U.S. Transportation.

Blumenberg, E. and Pierce, G. (2012). Automobile ownership and travel by the poor: Evidence from the 2009 national household travel survey. Transportation Research Record: Journal of the Transportation Research Board, 2320(1):28-36.

Blumenberg, E. and Smart, M. (2011). Migrating to driving: Exploring the multiple dimensions of immigrants' automobile use. In Lucas, K., Blumenberg, E., and Weinberger, R., editors, Auto motives: Understanding car use behaviours, pages 225-251. Emerald Group Publishing Limited., United Kingdom.

Bostock, L. (2001). Pathways of disadvantage? Walking as a mode of transport among low-income mothers. Health \& Social Care in the Community, 9(1):11-18. _eprint: https://onlinelibrary.wiley.com/doi/pdf/10.1046/j.13652524.2001.00275.x.

Bou Mjahed, L., Mittal, A., Elfar, A., Mahmassani, H. S., and Chen, Y. (2017). Exploring the Role of Social Media Platforms in Informing Trip Planning: Case of Yelp.com. Transportation Research Record, 2666(1):1-9. Publisher: SAGE Publications Inc.

Brobeck, S. and Hunter, J. R. (2012). Lower-income households and the auto insurance marketplace: Challenges and opportunities. Technical report, Consumer Federation of America, Washington DC.

Brown, A. E. (2017). Car-less or car-free? socioeconomic and mobility differences among zero-car households. Transport Policy, 60:152-159.

Chatman, D. G. (2013). Does tod need the t? Journal of the American Planning Association, 79(1):17-31.

Chu, Y.-L. (2002). Automobile ownership analysis using ordered probit models. Transportation Research Record: Journal of the Transportation Research Board, 1805(1):60-67.

Clark, B., Chatterjee, K., and Melia, S. (2015). Changes in level of household car ownership: the role of life events and spatial context. Transportation, 43(4):565-599.

Clifton, K. J. (2004). Mobility strategies and food shopping for low-income families: A case study. Journal of Planning Education and Research, 23(4):402-413.

Cross, R. J., Dutzik, T., Mierzwinski, E., and Casale, M. (2019). Driving into debt: The hidden costs of risky auto loans to consumers and our communities. Technical report, Frontier Group and U.S. PIRG Education Fund.

Curl, A., Clark, J., and Kearns, A. (2018). Household car adoption and financial distress in deprived urban communities: A case of forced car ownership? Transport Policy, 65:61-71. 
Currie, G. and Delbosc, A. (2011). Mobility vs. Affordability as Motivations for Car-Ownership Choice in Urban Fringe, Low-Income Australia. In Lucas, K., Blumenberg, E., and Weinberger, R., editors, Auto motives: Understanding car use behaviours, pages 193-208. Emerald Group Publishing Limited, United Kingdom, 1 edition.

Currie, G. and Delbosc, A. (2013). Exploring trends in forced car ownership in Melbourne. In 36th Australasian Transport Research Forum, Brisbane, Queensland, Australia.

Currie, G., Delbosc, A., and Pavkova, K. (2018). Alarming Trends in the Growth of Forced Car Ownership in Melbourne. In Australasian Transport Research Forum 2018 Proceedings, page 14.

Dodson, J. and Sipe, N. (2007). Oil Vulnerability in the Australian City: Assessing Socioeconomic Risks from Higher Urban Fuel Prices. Urban Studies, 44(1):37-62. Publisher: SAGE Publications Ltd.

Federal Reserve Board (2019). Report on the Economic Well-Being of U.S. Households in 2018. Technical report, The Board of Governors of the Federal Reserve System, Washington DC.

Fletcher, C. N., Garasky, S. B., Jensen, H. H., and Nielsen, R. B. (2010). Transportation access: A key employment barrier for rural low-income families. Journal of Poverty, 14(2):123-144.

Froud, J., Johal, S., Leaver, A., and Williams, K. (2005). Different worlds of motoring: Choice, constraint and risk in household consumption. The Sociological Review, 53(1):96-128.

Giuliano, G. and Dargay, J. (2006). Car ownership, travel and land use: a comparison of the us and great britain. Transportation Research Part A: Policy and Practice, 40(2):106-124.

GoFundMe.com (2015). Help james robertson get a car. [Online; accessed 2019-06-20].

GoFundMe.com (2019). How to find car repair financial assistance fast. [Online; accessed 2019-11-12].

Grengs, J., Levine, J., Shen, Q., and Shen, Q. (2010). Intermetropolitan comparison of transportation accessibility: Sorting out mobility and proximity in san francisco and washington, d.c. Journal of Planning Education and Research, 29(4):427-443.

Guo, Z. (2013). Residential street parking and car ownership. Journal of the American Planning Association, 79(1):32-48.

Halpern-Meekin, S., Greene, S. S., Levin, E., and Edin, K. (2018). The Rainy Day Earned Income Tax Credit: A Reform to Boost Financial Security by Helping Low-Wage Workers Build Emergency Savings. RSF: The Russell Sage Foundation Journal of the Social Sciences, 4(2):161-176. Publisher: RSF: The Russell Sage Foundation Journal of the Social Sciences.

Jeekel, H. (2016). The car-dependent society: a European perspective. Routledge, London, [England]. http://newcatalog.library.cornell.edu/catalog/11323034.

Jeon, J. S., Dawkins, C., and Pendall, R. (2018). How vehicle access enables low-income households to live in better neighborhoods. Housing Policy Debate, 0(0):1-20.

Jones, D. W. (2008). Mass motorization + mass transit : an American history and policy analysis. Indiana University Press, Bloomington.

Jones, P. (1987). Mobility and the Individual in Western Industrial Society. In Nijkamp, P. and Reichman, S., editors, Transportation planning in a changing world, pages 29-47. Gower in association with the European Science Foundation, Aldershot, Hants, England. http://newcatalog.library.cornell.edu/catalog/1318129.

Karger, H. J. (2003). No deals on wheels: How and why the poor pay more for basic transportation. Journal of Poverty, 7(4):93-112.

Katz, M. B. (2013). The undeserving poor: America's enduring confrontation with poverty. Oxford University Press, New York, second edition, fully updated and revised. edition. http://newcatalog.library.cornell.edu/catalog/8305642.

Kawabata, M. and Shen, Q. (2007). Commuting inequality between cars and public transit: The case of the san francisco bay area, 1990-2000. Urban Studies, 44(9):1759-1780.

Kenworthy, N., Dong, Z., Montgomery, A., Fuller, E., and Berliner, L. (2020). A cross-sectional study of social inequities in medical crowdfunding campaigns in the United States. PLOS ONE, 15(3):e0229760.

King, D. A., Smart, M. J., and Manville, M. (2019). The poverty of the carless: Toward universal auto access. Journal of Planning Education and Research, page 0739456X18823252.

Klein, N. J. and Smart, M. J. (2017). Car today, gone tomorrow: The ephemeral car in low-income, immigrant and minority families. Transportation, 44(3):495-510.

Klein, N. J. and Smart, M. J. (2019). Life events, poverty, and car ownership in the united states: A mobility biography approach. Journal of Transport and Land Use, 12(1). [Online; accessed 2019-05-20]. 
Leung, A., Burke, M., and Cui, J. (2018). The tale of two (very different) cities - Mapping the urban transport oil vulnerability of Brisbane and Hong Kong. Transportation Research Part D: Transport and Environment, 65:796-816.

Liao, Y., Gil, J., Pereira, R. H. M., Yeh, S., and Verendel, V. (2020). Disparities in travel times between car and transit: Spatiotemporal patterns in cities. Scientific Reports, 10(1):1-12. Number: 1 Publisher: Nature Publishing Group.

Lovejoy, K. and Handy, S. (2008). A case for measuring individuals' access to private-vehicle travel as a matter of degrees: lessons from focus groups with Mexican immigrants in California. Transportation, 35(5):601-612.

Lutz, C. (2014). The U.S. car colossus and the production of inequality. American Ethnologist, 41(2):232-245.

Martin, N. and Adams, O. (2012). Grand theft auto loans: Repossession and demographic realities in title lending. Missouri Law Review, 77(1):41-94.

Mattioli, G. (2017). "Forced car ownership" in the UK and Germany: socio-spatial patterns and potential economic stress impacts. Social Inclusion, 5(4):147-160.

Mattioli, G., Philips, I., Anable, J., and Chatterton, T. (2019). Vulnerability to motor fuel price increases: Socio-spatial patterns in England. Journal of Transport Geography, 78:98-114.

Mattioli, G., Wadud, Z., and Lucas, K. (2018). Vulnerability to fuel price increases in the UK: A household level analysis. Transportation Research Part A: Policy and Practice, 113:227-242.

Mitra, S. K. and Saphores, J.-D. M. (2017). Carless in california: Green choice or misery? Journal of Transport Geography, 65:1-12.

Mondschein, A. (2015). Five-star transportation: using online activity reviews to examine mode choice to non-work destinations. Transportation, 42(4):707-722.

Morduch, J. and Schneider, R. (2017). The Financial Diaries: How American Families Cope in a World of Uncertainty. Princeton University Press, Princeton, NJ. DOI 10.1515/9781400884599.

Mullen, C. and Marsden, G. (2018). The Car as a Safety-Net: Narrative Accounts of the Role of Energy Intensive Transport in Conditions of Housing and Employment Uncertainty. In Hui, A., Day, R., and Walker, G., editors, Demanding Energy: Space, Time and Change, pages 145-164. Springer International Publishing.

Mullen, C., Marsden, G., and Philips, I. (2020). Seeking protection from precarity? Relationships between transport needs and insecurity in housing and employment. Geoforum, 109:4-13.

Murphy, A. K. (forthcoming). Where the Sidewalks End: Poverty, Race, \& Community in an American Suburb. Oxford University Press, New York, NY.

Noble, S. U. (2018). Algorithms of oppression: how search engines reinforce racism. New York University Press, New York. http://newcatalog.library.cornell.edu/catalog/10237927.

Paulus, T. M. and Roberts, K. R. (2018). Crowdfunding a "real-life superhero": The construction of worthy bodies in medical campaign narratives. Discourse, Context \& Media, 21:64-72.

Prillwitz, J., Harms, S., and Lanzendorf, M. (2006). Impact of life-course events on car ownership. Transportation Research Record: Journal of the Transportation Research Board, 1985(1):71-77.

Radu, M. B. and McManus, L. (2018). A qualitative analysis of requests for financial help via gofundme by victims of intimate partner violence. Sociological Spectrum, 38(5):312-325.

Ralph, K. M. (2018). Childhood car access: Long-term consequences for education, employment, and earnings. Journal of Planning Education and Research, page 0739456X18798451.

Rau, H. and Manton, R. (2016). Life events and mobility milestones: Advances in mobility biography theory and research. Journal of Transport Geography, 52(Supplement C):51-60.

Rice, L. and Schwartz, E. J. (2018). Discrimination when buying a car: How the color of your skin can affect your shopping experience. Technical report, National Fair Housing Alliance.

Rock, S., Ahern, A., and Caulfield, B. (2016). The economic boom, bust and transport inequity in suburban Dublin, Ireland. Research in Transportation Economics, 57:32-43.

Salon, D. (2009). Neighborhoods, cars, and commuting in new york city: A discrete choice approach. Transportation Research Part a-Policy and Practice, 43(2):180-196.

Schneider, A. and Ingram, H. (1993). Social construction of target populations: Implications for politics and policy. American Political Science Review, 87(2):334-347.

Schweitzer, L. (2014). Planning and Social Media: A Case Study of Public Transit and Stigma on Twitter. Journal of the American Planning Association, 80(3):218-238. 
Shen, Q. (2001). A spatial analysis of job openings and access in a u.s. metropolitan area. Journal of the American Planning Association, 67(1):53-68.

Shin, E. J. (2019). What Can We Learn from Online Reviews? Examining the Reviews of Los Angeles Metro Rail Stations. Journal of Planning Education and Research, page 0739456X19870261. Publisher: SAGE Publications Inc.

Silge, J. and Robinson, D. (2017). Text mining with R: a tidy approach. O'Reilly, Bejing, first edition. edition.

Sipe, N. and Dodson, J. (2013). Oil Vulnerability in the American City. In Renne, J. L. and Fields, B., editors, Transport Beyond Oil, pages 31-50. Island Press/Center for Resource Economics, Washington, DC.

Snyder, J. (2016). Crowdfunding for medical care: Ethical issues in an emerging health care funding practice. Hastings Center Report, 46(6):36-42.

Snyder, J., Mathers, A., and Crooks, V. A. (2016). Fund my treatment!: A call for ethics-focused social science research into the use of crowdfunding for medical care. Social Science \& Medicine, 169:27-30.

Syed, S. T., Gerber, B. S., and Sharp, L. K. (2013). Traveling towards disease: Transportation barriers to health care access. Journal of Community Health, 38(5):976-993.

Tach, L., Halpern-Meekin, S., Edin, K., and Amorim, M. (2018). “As Good as Money in the Bank”: Building a Personal Safety Net with the Earned Income Tax Credit. Social Problems, 66(2):274-293.

Taylor, J., Bernard, M., Neil, H., and Creegan, C. (2009). The travel choices and needs of low income households: The role of the car. Technical report, Prepared for the Department for Transport by the National Center for Social Research.

The Pew Charitable Trusts (2015). The Role of Emergency Savings in Family Financial Security: How Do Families Cope With Financial Shocks? Technical report, The Pew Charitable Trusts.

U.S. Census Bureau (2019). 2018 American Community Survey 5-Year Estimates, Tables B01001 and B08201.

Walks, A. (2018). Driving the poor into debt? Automobile loans, transport disadvantage, and automobile dependence. Transport Policy, 65:137 - 149.

Weinberger, R. (2012). Death by a thousand curb-cuts: Evidence on the effect of minimum parking requirements on the choice to drive. Transport Policy, 20:93-102.

Widener, M. J. (2017). Comparing measures of accessibility to urban supermarkets for transit and auto users. The Professional Geographer, 69(3):362-371.

Zegras, C. (2010). The built environment and motor vehicle ownership and use: Evidence from santiago de chile. Urban Studies, 47(8):1793-1817. 